\title{
Application of PCR for the detection of bovine tuberculosis in cattle
}

\author{
Q. Nahar, M. Pervin, M. T. Islam ${ }^{1}$ and M. A. H. N. A. Khan \\ Department of Pathology, Bangladesh Agricultural University, Mymensingh-2202, Bangladesh \\ ${ }^{1}$ Department of Pathology and Parasitology, Patuakhali Science and Technology University, Khanpura, Babugonj, \\ Barisal-8210, Bangladesh
}

\begin{abstract}
The present study was carried out for the detection and identification of bovine tuberculosis (bTB) using polymerase chain reaction (PCR). A total of 10 suspected cattle of Savar and BAU dairy farm were examined. Lymphnode biopsy, nasal swabs and blood were collected. Smears from lymphnode biopsy and nasal swabs were made onto clear slides and stain with acid fast staining. Portion of lymohnodes were preserved at $-20^{\circ} \mathrm{C}$ and extracted DNA for PCR analysis. Portion of lymphnodes and other tissues were also collected in $10 \%$ neutral buffered formalin for routine Hematoxilin and Eosin staining and acid fast staining. In this study, acid fast staining of lymphnodes and nasal smears failed to detect acid fast Mycobacterium. The genome of bovine Mycobacterium in the extracted DNA of lymphnodes which used in PCR reaction was amplified and yielded $600 \mathrm{bp}$ amplicon. This study suggests that, the PCR technique is a useful and rapid diagnostic tool for the identification of bovine TB in dairy cattle. Amplification technology offers the potential for the diagnosis of TB in a few hours with a high degree of sensitivity and specificity.
\end{abstract}

Keywords: Bovine TB, acid fast, PCR

\section{Introduction}

Tuberculosis (TB) is an important zoonotic disease caused by an intracellular acid-fast organism Mycobacterium sp. It has been recognized from 176 countries as one of the important bovine diseases causing great economic loss (Hines et al., 1995; Martin et al., 1994; Samad, 2000). TB is a contagious disease, which can affect most warm-blooded animals, including human being (Radostits et al., 2000). Cattle, goats and pigs are the domestic species most susceptible to infection, while horses are relatively resistant to infection. In cattle, exposure to this organism can result in a chronic disease that jeopardizes animal welfare and productivity and in some countries leads to significant economic losses by causing ill health and mortality. Moreover, human TB of animal origin caused by $M$. bovis is becoming increasingly evident in developing countries Prasad et al., (2005).

The diagnosis of Mycobacterium-induced disease is most commonly made by direct sample examination and culture. Acid-fast bacilli detection has low sensitivity and specificity, and, at best, can only provide a preliminary diagnosis. Long time is necessary for $M$. bovis and $M$. tuberculosis growth and culture, nonfastidious microorganisms will eventually contaminate a small percentage of cultures (Kekkaku, 1998). Following preliminary screening of suspected samples using acid fast staining, isolation can be carried out in a bacteriological medium. However, cross-contamination among bovine carcasses, improper decontamination procedure and duration of isolation procedure (often 3 weeks and up to 8-10 weeks in liquid medium) jeopardizes the isolation of $M$. bovis. The lengthy duration of isolation procedure imposes an unavoidable delay in important decisions about outbreaks and of suspected herds put under restriction. Shorter time-span diagnostic procedures are required for quicker decision. Therefore, there is an urgent need for a rapid, safe, and reliable method to diagnose of bovine TB. The most promising technique for approaching this diagnostic dilemma is polymerase chain reaction (PCR). PCR has been used to amplify different regions of the mycobacterial genome, making it a good candidate for assisting with species identification in a variety of specimens. Indeed, several research groups have described different PCR protocols for Mycobacterium genome amplification. Based on these results, the US Food and Drug Administration (FDA) have approved the use of PCR as an aid for the diagnosis of TB in clinical samples. The rapid and accurate detection of Mycobacterium $s p$ is of paramount importance in the effective management of TB in man and animal. 


\section{Materials and Methods}

The samples were collected from suspected cattle of Savar and Bangladesh Agricultural University (BAU) dairy farms (previously PPD positive). The tuberculin test positive cattle of BAU dairy farm $(n=3)$ were euthanized with saturated $\mathrm{MgSO}_{4}$ and a thorough postmortem examination was carried out to investigate the gross lesions. The samples (liver, heart, lung, lymphnode and spleen) for histopathologic examination were collected and preserved in $10 \%$ neutral buffered formalin. Lungs, lymphnodes and spleen were snap freeze and preserved at $-20^{\circ} \mathrm{C}$ for PCR detection of TB. The formalin fixed tissues were processed, sectioned and stained with hematoxylin and eosin (H\&E) stain and acid-fast stain (Luna, 1968).

Extraction of DNA: DNA was extracted by locally adopted conventional method (Buckingham and Flaws, 2007). Briefly, a total of $200 \mathrm{mg}$ grained sample (lymphnodes) was taken in the microcentrifuge tubes containing $200 \mu \mathrm{l}$ cell lysis buffer and vortexed. The solution was centrifuged at $5000 \mathrm{rpm}$ for $10 \mathrm{~min}$ to collect the supernatant. Equal volume of phenol chloroform isoamyl alcohol was added to the supernatant and vortexed. Then the solution was centrifuged at $15000 \mathrm{rpm}$ for $3 \mathrm{~min}$ and the supernatant was collected. Thereafter $10 \mu \mathrm{l}$ of $5 \mathrm{M} \mathrm{NaCl}$ was added on the $90 \mu \mathrm{l}$ solution. Ice cool absolute alcohol of $250 \mu \mathrm{l}$ was added, centrifuged at $15000 \mathrm{rpm}$ for $10 \mathrm{~min}$ and the supernatant solution was colleted. The solution was desalted twice by using $80 \%$ ethanol. The tube was allowed to air dry for 15 minutes and $25 \mu$ of nuclease free water was added and stored at $4^{\circ} \mathrm{C}$. Thus the DNA samples were evaluated both quantitatively and qualitatively using spectrophotometer and agarose gel electrophoresis, respectively (Spectronic R GeneticsTM New York, USA).

Primer selection for PCR: The oligonucleotide primer used to detect the Mycobacterium bovis was listed in Table 1.

Table 1. Primers and their sequences used in the study

\begin{tabular}{|l|l|c|c|}
\hline Primer & \multicolumn{1}{|c|}{ Sequence } & Reference & $\begin{array}{c}\text { PCR products } \\
\text { size (bp) }\end{array}$ \\
\hline Forward & 5'-CAGGGATCCACCATGTTCTTAGCGGGTTG-3' & $\begin{array}{c}\text { Xiu-yun } \\
\text { et al., 2006 }\end{array}$ & 600bp \\
\hline Reverse & 5'-TGGCGAATTCTTACTGTGCCGGGGG -3' & \\
\hline
\end{tabular}

Polymerase chain reaction (PCR): $50 \mu \mathrm{l}$ PCR mix consisted of $25 \mu \mathrm{l}$ of $2 \mathrm{X}$ Master Mix (GeNei ${ }^{\mathrm{TM}}$ PCR Master Mix Kit), $1 \mu \mathrm{l}$ (10 pmol) of each primer, $3 \mu \mathrm{l}$ template DNA and $20 \mu \mathrm{l}$ nuclease free $\mathrm{H}_{2} \mathrm{O}$ and $3 \mu \mathrm{l}$ water was added instead of DNA to the water control tube. DNA amplification was carried out in a thermal cycler (Master Cycler Gradient, Eppendorf, Germany) using the thermal profile: $98^{\circ} \mathrm{C}$ for 5 min, one cycle; $95^{\circ} \mathrm{C}$ for $1 \mathrm{~min}, 56^{\circ} \mathrm{C}$ for $1 \mathrm{~min}, 72^{\circ} \mathrm{C}$ for $1 \mathrm{~min}, 30$ cycles; $72^{\circ} \mathrm{C}$ for $10 \mathrm{~min}$, one cycle. After completion of PCR reaction the tubes were held at $4^{\circ} \mathrm{C}$.

Electrophoresis: The amplified PCR products were separated electrophoresed in $1 \%$ agarose gel, stained with ethidium bromide and examined under UV light using an image documentation system (Spectronic R GeneticsTM New York, USA).

\section{Results and Discussion}

\section{Necropsy findings of suspected cattle}

The necropsy examination included enlarged and consolidated lungs with fibrin deposition (Fig. 1) and enlarged spleen (Fig. 3). Pipe steam liver was found in liver and the liver was severely necrosed (Fig. 2). Pipe steam liver indicates infection with fascioliosis which was appeared as risk factor for tuberculosis (Flynn et al., 2007). 


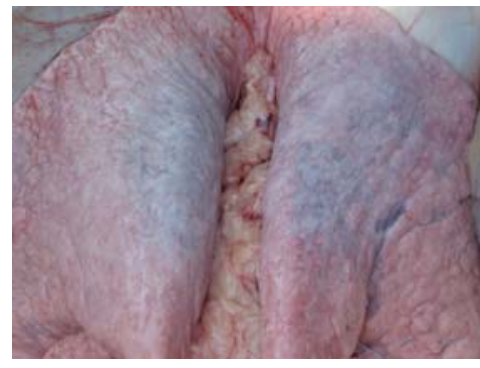

Fig.1. Lungs obtained from tuberculin +ve sample. The lungs were congested and consolidated at time of necropsy

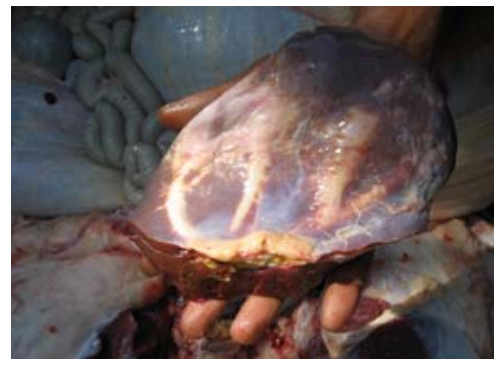

Fig. 2. Liver collected from cow +ve with tuberculin test at BAU dairy farm. The liver found to contain Fasciola (pipe steam liver, black arrow)

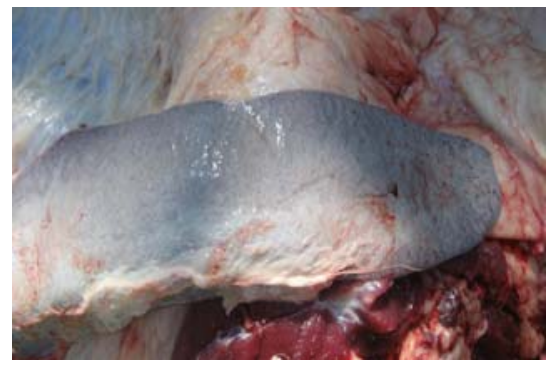

Fig. 3. Spleen obtained from a tuberculin +ve cow at BAU dairy farm. The spleen was enlarged

Acid-fast staining of impression smears: Impression smears stained with acid fast staining did not reveal acid fast organism (Fig. 4). The undetectable levels of Mycobacterium sp in impression smear of upper respiratory tract suggests that diseased cattle seldom shed the organism at detection levels in nasal discharges (Michel et al. 2007). Lymphnode aspirates were also subjected for smear preparation and acid fast staining. The acid fast organism was not detected in the lymph node aspirates smear (Fig. 5). It was suggested that although the cattle was tuberculin positive, the lymph node was enlarged but the organism left undetected as well (Vitale et al., 1998). The results of this study indicated that detection of acid fast organism in smears preparation is not a valid technique.

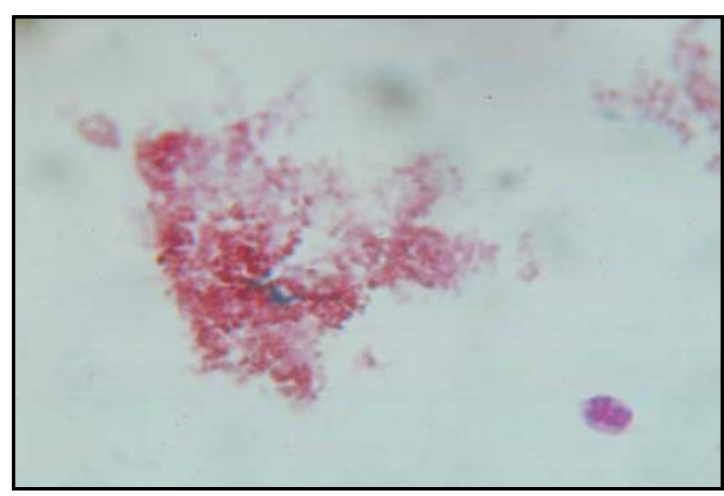

Fig. 4. Acid fast staining of impression smear taken from the upper respiratory tract of dairy cow. Acid fast organism was not seen in the clumps of nasal epithelium ( $X$ 82.5)

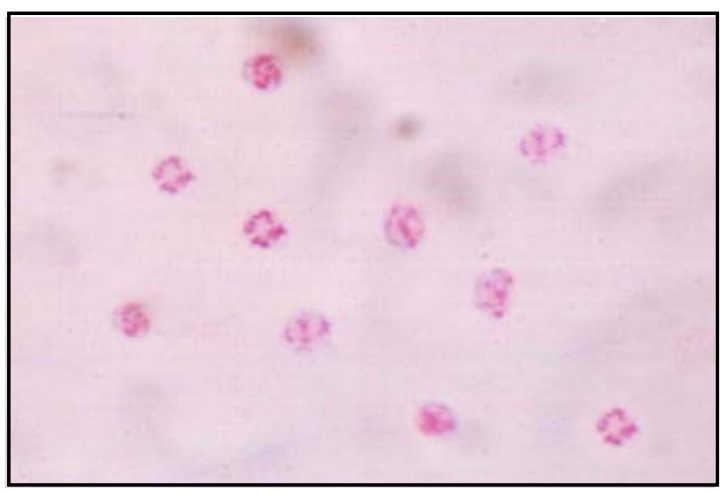

Fig. 5. Acid fast staining of lymphnode aspirates prepared from tuberculin reactor cows. Only the neutrophils and lymphocytes were detected under a high power objective (X 100)

\section{Histopathological examination}

Severe congestion and accumulation of fibrin in the lung parenchyma was seen. Mononuclear cellular infiltration, proliferation of fibrous connective tissue was seen in spleen (Fig. 6) and lungs (Fig. 7). The liver was cirrhotic and also showed granulomatous reaction. Acid fast organism was not seen in acid fast staining of lung, liver, spleen and lymohnode (Fig. 8 and 9) of a tuberculin +ve cow. The detection of acid fast organism in cattle positive to tuberculin test is not always convincing (Kekkaku, 2003). 


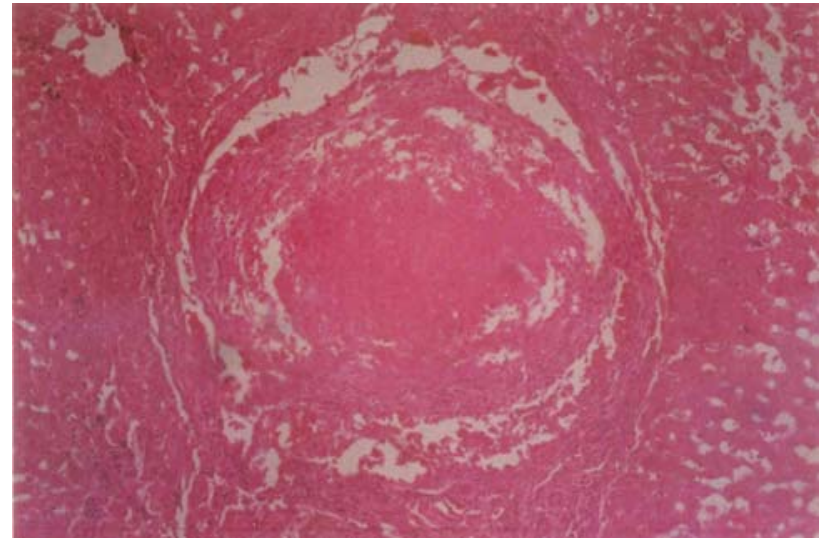

Fig. 6. A nodular lesion in the spleen of a suspected cow stained with $\mathrm{H}$ \& $\mathrm{E}(X$ 82.5). There was a core of necrotic tissues circumscribed by fibrous connective tissues. Tissues around the nodular lesion were congested and inflamed

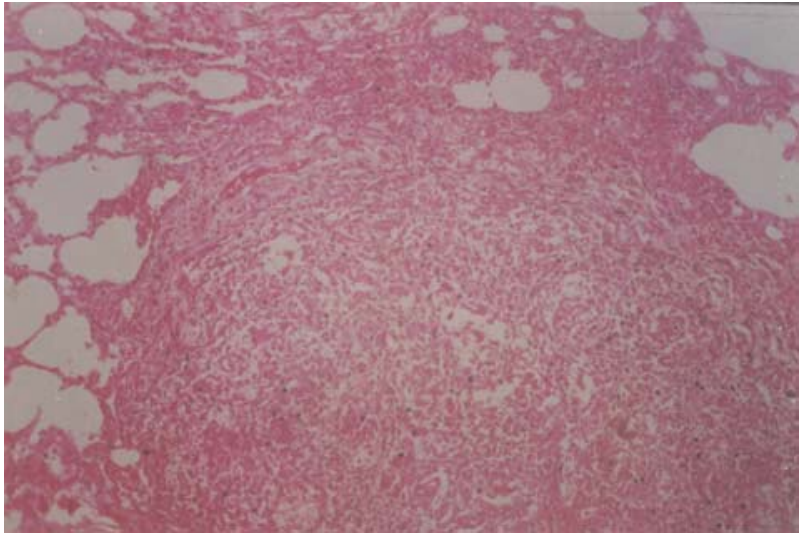

Fig. 7. A granulomatous nodule was seen in the lungs of tuberculin positive cow of BAU dairy farm and stained with H\&E. There was caseous necrotic center, which is surrounded by thick fibrous connective tissue capsule (X 82.5)

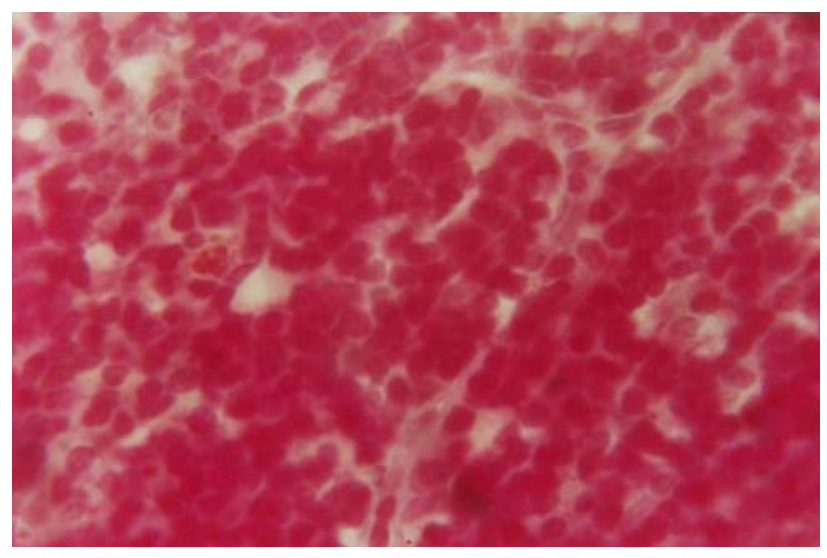

Fig. 8. Acid fast staining of lymphnode section of a tuberculin +ve cow. Acid fast bacilli was not seen in the stained section (X 330)

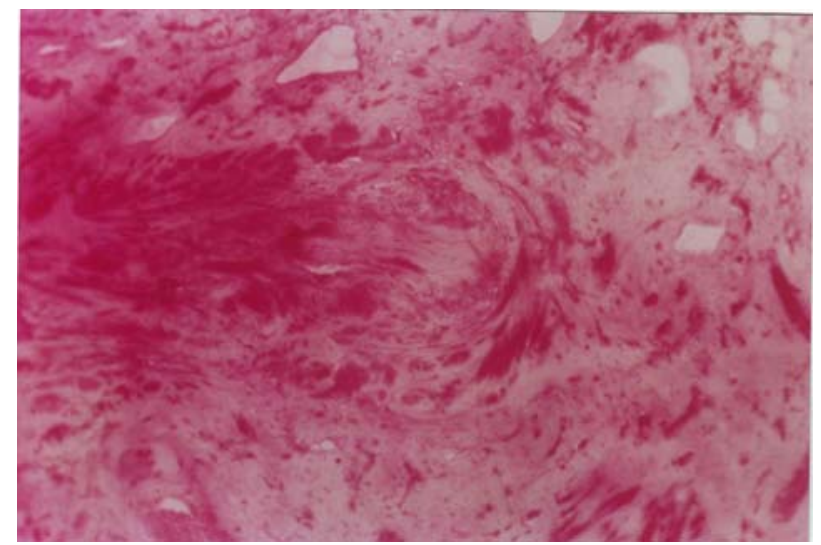

Fig. 9. Acid fast staining of liver section of a tuberculin +ve cow. Acid fast bacilli was not seen in stained tissue (X 330)

Polymerase chain reaction (PCR): The DNA of Mycobacterium bovis was amplified using commercial $\mathrm{GeNei}^{\mathrm{TM}}$ PCR Master Mix Kit and genus specific primer. The DNA of bovine Mycobacterium in the extracted DNA in PCR reaction was amplified and gave product of 600 bp, as expected (Fig. 10). 

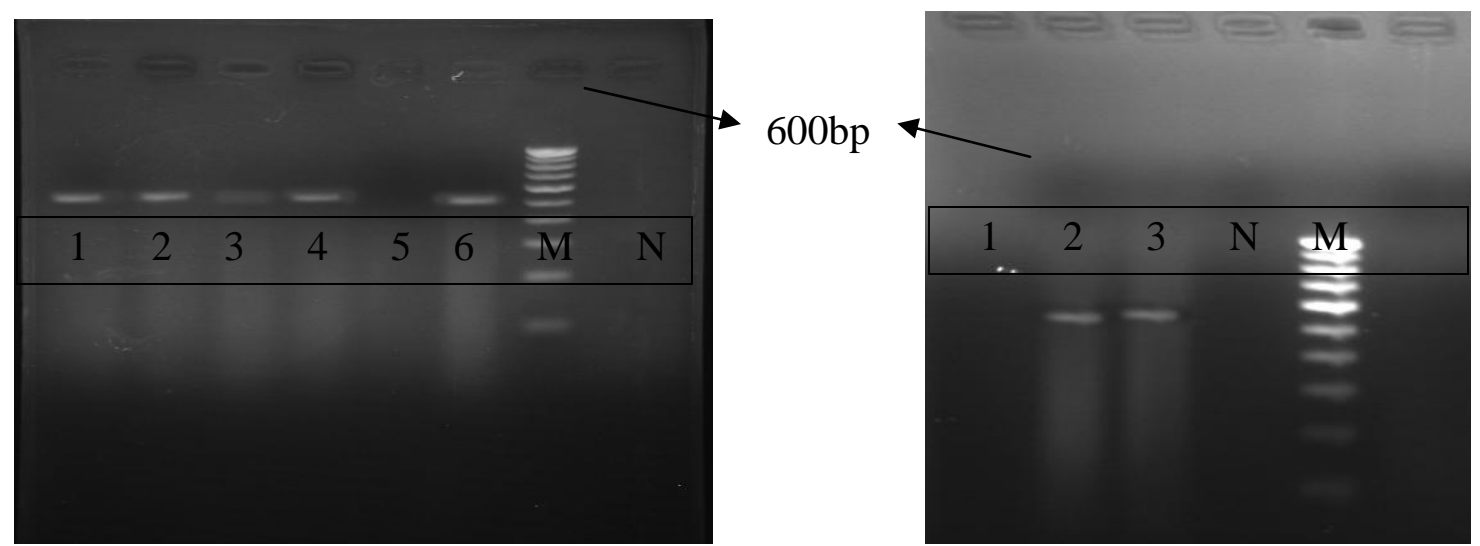

Fig. 10. Agarose gel electrophoresis of PCR products obtained from the lymphnode of dairy cattle and amplified using bovine Mycobacterium specific primers. M=Marker, lane 1, 2, 3, 4, 5 and 6 samples collected from Savar dairy farm (a) and lane 1,2 and 3 (b) is for the sample collected from BAU dairy farm. $N=$ negative control. Lane 1, 2, 3, 4 and 6 from the savar dairy farm and lane 2 and 3 from the BAU dairy farm amplified band (595bp) specific for M. bovis and indicating tuberculous infection

This study provides evidence that PCR is a sensitive screening assay for the detection of Mycobacterium bovis DNA in lymph nodes of cattle (Taylor et al., 2007; Sreedevi and Krishnappa, 2003; Romero et al., 1995; Liébana et al., 1995). PCR can generally be used to diagnose bovine TB in field condition.

\section{Conclusion}

The present study was conducted principally to develop an effective method for the rapid and sensitive diagnosis of bovine TB in dairy cattle. There are various methods for diagnosis of bovine TB. The definitive diagnosis relies on time-consuming, highly specialized and laborious biochemical tests. For eradication of bovine tuberculosis, a definitive diagnosis depends on the isolation of Mycobacterium bovis. PCR method is rapid, sensitive, and specific tool for diagnosis of bovine TB. In this study all the cattle were positive to tuberculin test but in acid fast staining acid fast organism were not seen in any cases of bovine TB. The result of PCR technique revealed that out of nine samples, seven (88\%) gave amplified band indicating positive and higher sensitivity of the technique. Rest of the samples failed to yield amplicon specific for $M$ bovis infection and this could due to fact that the cattle may be infected with Mycobacterium $s p$ other than $M$. bovis, require further investigation.

\section{References}

Buckingham, L. and Flaws, M.L. 2007. Molecular diagnostics: fundamental Methods and clinical Application, F. A. Davis, Philadelphia, $\mathrm{Pa}$, USA.

Flynn, R.J, Mannion, C., Golden, O., Hacariz, O. and Mulcahy G. 2007. Experimental Fasciola hepatica Infection Alters Responses to Tests Used for Diagnosis of Bovine Tuberculosis. Infect. Immun. 75(3): 1373-1381.

Hines, M.E., Kreeger, J.M. and Smith, P.K. 1995. Microbacterial infections of animals. Pathology and Pathogenesis. Lab. Anim. Sci.: 45: 334-351.

Kekkaku. 1998. Laboratory media for the cultivation of tubercle bacillus. Article in Japanese: 73(5):329-37.

Kekkaku. 2003. Standardization of laboratory tests for tuberculosis and their proficiency testing. . Article in Japanese:78(8):541-51.

Liebana, E., Aranaz, A., Mateos, A., Vilafranca, M. and E Gomez-Mampaso, E. 1995. Simple and rapid detection of Mycobacterium tuberculosis complex organisms in bovine tissue samples by PCR. J. Clin. Microbiol: 33(1): 33-36.

Luna, L. 1968. Manual of histologic staining methods of the armed forces institute of pathology. 3rd ed. Mcgraw- hill.inc. Book Company, New York.

Martin, S.W., Dietrich, R.A., Genno, P., Heuschele, W.P., Jones, R.L., Koller, M., Lee, J.D., Lopez, H.C., Moon, H.W., Robinson, R. A., Smith, P.L and Williams, G.W. 1994. Livestock disease eradication: Evaluation of the cooperative state federal bovine tuberculosis eradication program. National Academy of Sciences, Washington D.C. pp. 1-97. 
Michel, A.L., Klerk, L.D., Pittus, N.G., Warren, R.M. and Helden, P.V. 2007. Bovine tuberculosis in African buffaloes: observations regarding Mycobacterium bovis shedding into water and exposure to environmental Mycobacteria. BMC Veterinary Research, 3: 3.

Prasad, H.K., Singhal, A., Mishra, A., Shah, N.P., Katoch, V.M., Thakral, S.S. and others. 2005. Bovine tuberculosis in India: Potential basis for zoonosis. Tuberculosis. Vol. 85(5.6). pp. 421-428.

Radostis, O.M., Gay, C.C., Blood, D.C and Hinchdiff, K.W. 2000.Veterinary Medicine, A text book of the diseases of cattle, sheep, pigs, goats and horses.9th edition. 909-917 p. Michel, A.L.,Klerk L.D., Pittus,N.G.,Warren, R. M. and Helden, P.V. 2007, Bovine tuberculosis in African buffaloes: observations regarding Mycobacterium bovis shedding into water and exposure to environmental mycobacteria. BMC Veterinary Research, 3:23

Romero, R.E., Garzon, D.L. 1995. M. bovis in bovine clinical samples by PCR species-specific primers. Canadian J. Vet. Res. 63(2): 101-106.

Samad, M.A. 2000. Animal Husbandry and Veterinary Science. 1st pub. LEP Pub No. 11, BAU Campus, Mymensingh, Bangladesh.

Sreedevi, B. and Krishnappa, G. 2003. Detection of Mycobacterium tuberculosis complex organisms in clinical samples of cattle by PCR and DNA probe methods. Indian J. Comp. Microbiol., Immunol. \& Infect. Dis. 24(2): 167-171.

Taylor, G.M., Worth, D.R., Palmer, S., Jahans, K. and Hewinson, R.G..2007. Rapid detection of Mycobacterium bovis DNA in cattle lymph nodes with visible lesions using PCR. : BMC Vet Res. 13; 3:12.

Vitale, F., Capra, G., Maxia, L., Reale, S., Vesco, G. and Caracappa, S. 1998. Detection of Mycobacterium tuberculosis Complex in Cattle by PCR Using Milk, Lymph Node Aspirates, and Nasal Swabs. J.Clin. Microbiol, p.1050-1055, Vol. 36, No. 4.

Xiu-yun, J., Wang, C., Zhang, P. and Zhao-yang, H. 2006. Cloning and Expression of Mycobacterium bovis Secreted Protein MPB83 in Escherichia coli. J. Biochem. \& Molecul. Biol. Vol. 39, No. 1, pp. 22-25. 